EESTI NSV TEADUSTE AKADEEMIA TOIMETISED. XVI KÖIDE

KEEMIA * GEOLOOGIA. 1967, Nr. 3

ИЗВЕСТИЯ АКАДЕМИИ НАУК ЭСТОНСКОЙ ССР. ТОМ ХVI

ХиМИЯ * ГЕОЛОГИЯ. 1967. № 3

КАРЛ ОРВИКУ

\title{
РАЗВИТИЕ ГЕОЛОГИЧЕСКИХ НАУК В СОВЕТСКОЙ ЭСТОНИИ
}

Развитие геологических наук в Эстонии в течение последних 50 лет четко разделяется на два периода, сильно отличающихся друг от друга: период буржуазной власти (1918-1940 гг.) и период Советской власти, начавшийся в Эстонии в 1940 году.

В буржуазной Эстонии единственным научно-исследовательским учреждением, в котором выполнялись геологические исследования, долгие годы был Тартуский университет. Геологические исследования, в основном коренных пород, выполнялись здесь преподавателями кафедры геологии, а геоморфологические - преподавателями кафедры географии. Но поскольку число преподавателей на кафедрах было очень невелико, не могло быть и речи о выполнении планомерных и систематических теоретических исследований геологии территории республики.

В буржуазной Эсгонии имелось еще Горное управление при Министерстве промышленности, основная задача которого состояла в надзоре за горной промышленностью и выполнении небольших поисковых работ. Необходимо отметить, что в рамках последних проводились в небольшом объеме и буровые работы.

Определенную роль в изучении геологии и геоморфологии территории Эстонии играли также Общество естествоиспытателей при Тартуском университете и Көмиссия краеведения при Эстонском литературном обществе.

Положение геологических наук мало изменилось и после 1937 года, когда был учрежден Государственный геологический комитет, так как его небольшой коллектив был занят в основном поисками и разведкой полезных ископаемых (фосфориты, глины) и геологической съемкой.

Несмотря на очень ограниченные возможности, существовавшие для теоретических геологических исследований в буржуазной Эстонии, в 1918-1940 годах был все же достигнут ряд существенных научных результатов.

Изучались в основном стратиграфия и палеонтология палеозойских отложений. Значительно были дополнены знания о стратиграфии нижнего кембрия, нижнего ордовика и кукрузеского горизонта, стратиграфии силура, в частности верхнего, и верхнего девона. Были составлены монографии, в частности брахиопод, а также мшанок, трилобитов, началось изучение остракод и др. Специальные литологические исследования коренных пород были начаты только в последние годы рассматриваемого периода в основном для решения литостратиграфических проблем,

В меньшем объеме выполнялись исследования по четвертичной геологии и геоморфологии. Эти работы были направлены в основном на выяснение стратиграфии плейстоцена и голоцена, используя для этого палинологический метод, на выяснение древних береговых образований, 
геологии последнего оледенения и геоморфологии Североэстонского глинта. Необходимо отметить также исследования по ландшафтному районированию территории республики. Была составлена обзорная комплексная карта четвертичных отложений и геоморфологии.

Выполнялись также небольшие работы по исследованию подземных вод республики, но серьезные гидрогеологические исследования отсутствовали; не было и серьезных исследований по инженерной геологии.

Не выполнялись геофизические исследования для выяснения геологических структур, в частности кристаллического фундамента. В ходе общего изучения магнитного поля Балтийского моря и прилегающих территорий все же была выявлена сильная магнитная аномалия Йыхви, где были заложены две глубокие скважины (505 и 721 м), благодаря которым в кристаллическом фундаменте было установлено наличие породы со средним содержанием железа $20-25 \%$. На основании общей схемы магнитного поля территории была создана первая схема геологического строения кристаллического фундамента в пределах республики.

Необходимо также отметить, что в 30-х годах было выяснено метеоритное происхождение Каалиских кратеров на острове Сааремаа.

О научных направлениях и результатах в области геологических наук, достигнутых в 1918-1940 годах, можно получить обзор по непериодической серии «Труды Геологического института Тартуского университета», в которой с 1924 года было опубликовано более 60 работ разного объема и содержания.

В связи с тем, что в рассматриваемые годы в Эстонии практически не было специальных геологических научно-исследовательских и производственных учреждений, подготовка геологов в университете была очень ограничена. Вследствие этого и кадры геологов были очень немногочисленны как в начале, так и в конце этого гериода.

Восстановление Советской власти в Эстонии в 1940 году ознаменот вало начало нового этапа и в развитии геологических исследований. Уже в первый довоенный год Советской власти (лето 1940 - лето 1941 гг.) объем геологических производственных исследований резко увеличился, велась подготовка к организации специального геологического научно-исследовательского учреждения, предусматривалось расширение подготовки специалистов-геологов в Тартуском университете. Но осуществление этих қоренных изменений в развитии геологических наук в республике было прервано более чем на три года начавшейся в июне 1941 года Великой Отечественной войной. Развитие геологических наук в республике в условиях Советской власти смогло реально начаться только с осени 1944 года, когда территория Эстонской ССР была окончательно освобождена от фашистских оккупантов.

Научно-исследовательские работы пришлось в Эстонии после войны начать в очень трудных условиях, так как учреждения, занимавшиеся до войны геологическими исследованиями, потеряли большую часть своих кадров и материальной базы. В первые послевоенные годы нам помогали выполнять необходимые производственные геологические исследования многие всесоюзные геологические учреждения, в частности Северо-Западное геологическое управление МГ СССР и др.

Сушественную роль в изучении геологии территории республики сыграли стратиграфические, палеонтологические и др. исследования, выполненные Всесоюзным научно-исследовательским геологическим институтом (ВСЕГЕИ), Всесоюзным нефтяным научно-исследовательским геологоразведочным институтом (ВНИГРИ), Ленинградским государственным университетом и рядом других научных учреждений братских союзных республик. 
С 1957 года, когда было организовано Управление геологии при Совете Министров Эстонской ССР, геологические исследования производственного уклона - комплексная геологическая съемка, поиски и разведка полезных ископаемых, гидрогеологические изыскания и др. выполняются последним. За десять лет Управление геологии стало самым крупным геологическим учреждением республики, удовлетворяя своими исследованиями, в основном прикладного характера, соответствующие запросы народного хозяйства. Оно является в полном смысле слова детищем Советской власти в Эстонии и свидетельствует о тех больших возможностях, которые открылись для геологических работ благодаря установлению в республике социалистического строя.

Кроме геологических исследований прикладного характера, Управление геологии при СМ ЭССР изучает также теоретические проблемы геологии республики, в частности проблемы тектоники, оруденения и геологического строения кристаллического фундамента. Необходимо отметить, что Управленнем геологии при СM ЭССР издан XXVIII том («Эстонская ССР») монографической серии «Геология СССР» (1960) и ХХX том («Эстонская ССР») монографической серии «Гидрогеология CССР» $(1966)$.

Начиная с первых послевоенных лет в ряде проектных институтов, в частности в «Эстонпроекте» и «Эстпромпроекте», выполнен большой объем инженерно-геологических изысканий, которых в предыдущий период проводилось очень мало.

Организации Управления геологии при СМ ЭССР несомненно способствовало то, что к моменту его создания и в последующие годы мы располагали уже местными кадрами специалистов, получившими подготовку в послевоенные годы в Тартуском государственном университете. В последнем, учитывая крайний недостаток геологов в республике после войны, с осени 1945 года началась подготовка молодых специалистов, продолжающаяся и по сей день. В геологических учреждениях сейчас работают в основном геологи, получившие подготовку в ТГУ. Ведется в университете и серьезная научно-исследовательская работа, в частности в области ряда теоретических проблем геологии коренных пород и четвертичного периода Эстонии.

Основным научно-исследовательским учреждением, в котором ведутся геологические исследования теоретического характера, является Йнститут геологии Академин наук Эстонской ССР, созданный в 1947 году.

С первых же дней работы Институт геологии приступил к комплексному исследованию геологии территории Эстонской ССР, обращая особое внимание на исследование биостратиграфии и литологии палеозойских пород, вопросы геологии четвертичного периода, изучение тектонических структур кристаллического фундамента и осадочной толщи геофизическими методами, вопросы гидрогеологии. Общая цель всех этих исследований состояла в выяснении закономерностей геологического строения и развития территории Эстонии. С течением времени вышеназванные научные направления института уточнялись и модифицировались, но в принципе они и сейчас остаются ведущими в его деятельности. Институтом достигнут ряд научных результатов, имеющих общетеоретическое значение и способствуюших разрешению тех или иных народнохозяйственных проблем, в частности вопросов по использованию полезных ископаемых. Необходимо отметить, что в первые годы институту пришлось выполнить множество работ по:поиску и установленню запасов полезных ископаемых республики. Уточнялись запасы горючего сланца, велись поиски месторождений фосфоритов п глин.

С 1.956 года результаты научно-исследовательских работ института 
публикуются в основном в «Трудах» института, а также в виде сборников статей или отдельных книг. К концу 1966 года опубликовано 20 выпусков «Трудов», общий объем которых превышает 250 печатных листов. Кроме того, многие статьи печатаются в соответствующей серии журнала «Известия АН ЭССР» и в других периодических изданиях.

Необходимо отметить, что при Академии наук Эстонской ССР имеется Геологический музей, входящий в структуру Ннститута геологии АН ЭССР. В этом музее сосредоточены основные научные фондовые коллекции по геологии Эстонии, в том числе и многие керны глубоких бурений с территории республики. Последние хранятся на базе института в Пюсси (в районе Эстонского месторождения прибалтийского горючего сланца - кукерсита).

Из всего сказанного следует, что в Советской Эстонии существуют три основных геологических учреждения, каждое из которых выполняет свои специфические задачи в развитии геологических наук в республике и взаимно дополняет друг друга: Тартуский государственный университет, готовящий основные кадры молодых геологов, Управление геологии при СМ Эстонской ССР, главная задача которого состоит в выполнении геологических исследований производственного уклона, и Институт геологии Академии наук Эстонской ССР, основной задачей которого является теоретическое исследование геологических проблем.

\section{Исследования по геологии палеозоя}

Характерной частью геологического строения территории Эстонии является осадочная толща палеозойского возраста (кембрий, ордовик, силур, девон). С исключилельной полнотой представлены слои ордовика и силура, содержащие в большом количестве хорошо сохранившиеся окаменелости, а также наиболее существенные полезные ископаемые (горючий сланец, фосфорит, строительные материалы) республики. Этим и объясняется то, что изучению палеозойских пород уделяют большое внимание уже более ста лет. Но особенно расширились соответствующие исследования только в последнее десятилетие, при этом ведущую роль играют работы, выполняемые в Институте геологии АН ЭССР.

Первоочередной задачей было и остается еше в течение нескольких лет уточнение стратиграфии ордовика и силура. При решении этой проблемы учитываются как палеонтологические, так и литологические характеристики слоев. Это нашло свое выражение в том, что, кроме биостратиграфических работ, в основу которых положено монографическое изучение тех или других групп фауны, выполнены и литостратитрафические работы по ордовику и силуру. Ревизии стратиграфических схем способствует то, что благодаря богатому буровому материалу мы располагаем соответствующим геологическим материалом не только с узкой полосы выхода тех или иных слоев, а с большой территории. Это позволяет решать не только вопросы стратиграфии, но и вопросы распространения и развития фауны, образования пород и фации, а также вопросы палеогеографического характера значительно шире и глубже, чем до сих пор.

Много внимания уделено на уточнение стратиграфии ордовика, с которым связаны такие полезные ископаемые, как горючий сланец и фосфорит. Опубликован ряд описаний горизонтов (кейлаского, оандуского и др.), монографически изучены ругозы, мшанки, остракоды, строматопороидеи, частью наутилоидеи, брахиоподы и трилобиты, начато изучение конодонтов. На основании этих новых исследований дана 
уточненная стратиграфическая схема ордовика Эстонии, проведена корреляция этой схемы с соответствующими схемами смежных районов Ленинградской области, Латвии, Скандинавии. Выполненные исследования позволили дать монографический обзор биостратиграфии ордовика Северной Эстонии и такой же обзор истории развития Балтийского бассейна в ордовике, в котором дана детальная биостратиграфическая характеристика ордовикских отложений этого бассейна с выделением в нем трех основных фациальных зон, установлены главные этапы геологического развития его и на этой основе предложена уточненная единая стратиграфическая схема ордовика Прибалтики и прилегающих областей.

Крупные результаты можно отметить также по изученню стратиграфии силура, которое ведется комплексно, т. е. совместно с палеонтологами и литологами. Из групп фауны силура изучались монографически ругозы, табуляты, строматопоры, остракоды, начато изучение брахиопод и граптолитов. Детально изучаются карбонатные породы силура. Монографическое обобщение стратиграфии силура будет закончено в ближайшее время.

Так как уточнение и совершенствование стратиграфических схем ордовика и силура Эстонии уже достигли уровня, на базе которого можно вполне удовлетворительно решать как теоретические, так и практические вопросы, то в ближайшем будущем предусмотрено усилить комплексные литофациальные и палеоэкологические исследования ордовика и силура.

В последние годы ведутся систематические работы и по изучению стратиграфии терригенных пород палеозоя Әстонии. Так как соотгетствующие слои бедны окаменелостями, то для выяснения стратиграфии их используются в основном литолого-минералогические и геохимические методы исследования. Детально изучены оболовые песчаники пакерортского горизонта (ордовик), успешно решаются вопросы стратиграфии практически немых нижнекембрийских отложений (балтийская и валдайская серии), выполняются литолого-минералогические исследования девонской песчанистой толши. Все большее значение приобретают литофациальные исследования и при изучении терригенных пород палеозоя Эстонии.

Литолого-минералогические исследования палеозойских отложений имели также целью выяснить вещественный состав, закономерности образования и распространения соответствующих полезных ископаемых - ордовикских горючих сланцев, фосфоритов и др.

Особое место среди этих исследований занимают работы по изучению вещественного состава и условий образования горючего сланца. Установлены закономерности соотношений и распространения основных компонентов - органического вещества, карбоната кальция и терригенной части - в каждом слое сланца. Это дало возможность решать практические вопросы подготовки сланцевого топлива разного качества и состава. В дальнейшем предусмотрено продолжать литолого-минералогические и геохимические исследования палеозойских пород с целью повышения экономической эффективности использования полезных ископаемых.

Уже было обращено внимание на то, что в связи с усовершенствованием стратиграфических схем ордовика и силура успешно изучается ряд групп фауны ордовика и силура (ругозы, строматопороидеи, табуляты, остракоды и др.). Значительные успехи достигнуты и в изучении фауны девонских рыб (псаммостеид и артродир). Эти монографические

2 ENSV TA Toimetised $\mathrm{K} * \mathrm{G}-3 \quad 1967$ 
палеонтологические исследования будут продолжены и в дальнейшем, так как это необходимо для решения как стратиграфических вопросов, так и вопросов осадконакопления и палеоэкологии.

\section{Исследования по геологии четвертичного периода}

Исследования по геологии четвертичного периода, выполняемые в Эстонии, характеризуются комплексностью - это обусловлено тем, что в большинстве случаев отложения и формы рельефа того или иного генетического типа четвертичного периода образовались одновременно, и поэтому совместное изучение их дает лучшие результаты при выяснении условий образования соответствующих отложений и форм рельефа, а также при уточнении стратиграфической схемы четвертичных отложений и при палеогеографических построениях.

Вопросы четвертичной геологии Эстонии в довоенное время изучались значительно меньше, чем геология палеозоя республики; не было и сводки по четвертичной геологии и геоморфологии Эстонии. В 50-х годах такая сводка по четвертичным отложениям и геоморфологии была составлена. Эти обобщения значительно способствовали дальнейшему исследованию четвертичной геологии и решению вопросов прикладной геологии. Одновременно с работами по обобщению материалов по четвертичной геологии и геоморфологии начались исследования ряда. генетических типов отложений и форм рельефа.

Ввиду существенной роли отложений и форм рельефа последнего оледенения в Эстонии много внимания уделено выяснению распространения, строения и условий образования отложений и форм рельефа плейстоценовых оледенений. Соответствующие исследования будут одними из основных и в ближайшие годы. Хорошие результаты получены уже по исследованию озов и краевых образований Северной Эстонии, где они представлены в большом разнообразии и хорошо выражены. Эти исследования дали возможность уточнить и характер отступания последнего оледенения с территории Северной Эстонии. Успешно ведутся литолого-минералогические исследования морен, в частности количественными методами, что дало возможность уточнить стратиграфию моренных толщ, а также уточнить стадии последнего оледенения: на территории Эстонии. Комплексные литолого-минералогические исследования будут и в дальнейшем играть значительную роль среди исследований четвертичной геологии Эстонии.

Вторым основным направлением в исследовании четвертичной геологии Эстонии является изучение древних и современных береговых: образований. Геология древних береговых образований изучалась в основном геоморфологическими и палинологическими, а в последние годы и литологическими методами, что дало возможность значительно детализировать возрастные соотношения древних береговых образований, начиная с позднеледниковых береговых образований Балтийского приледникового озера'и кончая позднеголоценовыми береговыми образованиями Лимниевого моря. Выполненные работы дали возможность уточнить также палеогеографические условия трансгрессии и регрессии Балтийского моря на территории Эстонии. Продолжение этих работ откроет возможность в недалеком будущем составить монографическуюсводку древних береговых образований Балтийского моря в Эстонии. Еще в начальной стадии находятся исследования современного морского берега, которые направлены на установление закономерностей строения и развития прибрежных отложений и форм рельефа в условиях суммарного поднятия земной коры. В ходе этих работ выпол- 
няются и подводные геологические исследования. В связи с исследованиями древних и современных береговых образований геологическими методами изучаются также современные и голоценовые тектонические колебания земной коры в пределах территории Эстонии.

Для лучшего познания геологического строения и развития территории Эстонии в голоцене изучались распространение и закономерности строения и развития карста в известняковых породах Северной Эстонии, геология и стратиграфия озерной извести и источниковой извести, строение и развитие речных долин Северной и Южной Эстонии. Выполнен ряд исследований регионального характера - изучены геология четвертичных отложений возвышенности Сакала, геологическое развитие озера Выртсъярв и др.

При изучении четвертичной геологии Эстонии много внимания уделяется также уточнению стратиграфии четвертичных отложений. Эти работы ведутся в основном с применением палинологического метода. C помощью последнего достигнуты новые результаты по расчленению плейстоценовых отложений, включая и позднеледниковые отложения; уточнена также стратиграфия голоцена. При стратиграфических исследованиях все больше используются определения абсолютного возраста отложений радиоуглеродным методом, выполняемые соответствующей лабораторией Института зоологии и ботаники АН ЭССР в Тарту.

\section{Исследование тектонических структур геофизическими методами}

Кристаллический фундамент южного склона Балтийского щита архейского и протерозойского возраста на территории Эстонии, покрытый осадочной толщей мощностью до нескольких сотен метров, еще в конце 40-х годов был сравнительно слабо изучен. Так как для территории Эстонии тогда еще не существовало картины гравитационного и магнитного полей, которая могла бы быть использована для выяснения геологического строения кристаллического фундамента. Институт геологии в течение ряда лет выполнял гравиметрические и магнитометрические исследования, в результате которых были выяснены геофизические поля территории Эстонии, которые затем использовались для выяснения геологических структур кристаллического фундамента.

Разработаны общие черты геологического строения кристаллического фундамента Эстонии, послужившие необходимой основой для дальнейших детальных исследований кристаллического фундамента, которые уже начаты. Изучается детально ряд районов со значительными геофизическими аномалиями в Северной и Центральной Эстонии, например магнитная аномалия Кыхви, геофизические аномалии в районе Ульясте и Выхма, позволившие уточнить структуры пород с перспективными рудопроявлениями. В ближайшие годы в республике геофизические исследования будут сосредоточены на дальнейшем более углубленном изучении структурных особенностей кристаллического фундамента с целью выработать критерии прогноза полезных ископаемых в кристаллическом фундаменте.

В республике начато также петрографическое изучение пород кристаллического фундамента, что оказалось возможным благодаря глубоким бурениям, выполняемым Управлением геологии СМ ӘССР. Учитывая перспективность установления в кристаллическом фундаменте южного склона Балтийского щита рудных месторождений, комплексное изучение кристаллического фундамента представляет собой одну из наиболее существенных научных проблем, решением которой геологам Әстонии придется заниматься в ближайшие годы. 
Необ́ходимо отметить, что в послевоенные годы много внимания обращалось также на изучение рудопроявлений полиметаллов в осадочной толще Северной Эстонии.

В осадочной толще Северо-Восточной Эстонии распространены зоны тектонических нарушений северо-восточного простирания, усложняющие добычу сланца шахтным способом. В начале $50-x$ годов работами Института геологии было доказано, что эти зоны тектонических нарушений могут быть установлены методами электроразведки. Внедрение этих результатов в практику разведки горючих сланцев имело большое экономическое значение. И в последуюшие годы продолжались исследования зон тектонических нарушений, которые позволили в 1965 году разработать новую комплексную методнку злектроразведки, микромагнетометрии и геологических исследований для быстрого и дешевого выяснения геологического строения и точного местоположения зон тектонических нарушений и связанных с ними закарстованных участков, что способствует решению вопросов устойчивости кровли горных выработок около трещиноватых и закарстованных зон в осадочной толще. Методы электроразведки использованы также для установления рельефа коренных пород и мощности четвертичных отложений.

В последние годы начаты поисковые исследования по выяснению возможностей использования гравиметрических методов для установления современных вертикальных движений земной коры и для выяснения причин и закономерностей этих движений в связи с поднятием Балтийского щита и изменением плотности субстрата. Для этого организована сеть гравиметрических пунктов высокой точности, которая используется для повторных измерений силы тяжести; используется для этой цели также гравиметрическая станция Института геологии.

\section{Гидрогеологические и инженерно-геологические исследования}

Еще в первые послевоенные годы подземные воды Әстонии были слабо изучены, отсутствовал сводный гидрогеологический обзор. В то же время восстановление и развитие народного хозяйства требовали решения многих вопросов, связанных с водоснабжением промышленности, городов, сельского хозяйства. Учитывая это, Институт геологии развернул исследования подземных вод. В результате многолетних работ, выполненных в институте, выяснены водоносные горизонты, выделены гидрогеологические районы, установлены химизм и режим подземных вод по горизонтам, а также условия формирования подземных вод Эстонин. Эти исследования, окончившиеся в 1965 г. представлением монографической сводки по гидрогеологии Эстонии, во многом помогли решению вопроса водоснабжения в республике и заложили прочную основу для дальнейших более углубленных исследований ее гидрогеологии, которые сейчас выполняются в основном Институтом геологии АН ЭССР и Управлением геологии СМ ЭССР.

Изучался и изучается ряд специальных проблем гидрогеологии республики, связанных главным образом с решением вопроса о формировании подземных вод. Здесь необходимо особо назвать исследования подземных вод Таллина и некоторых других городов, изучение вопроса о встречаемости минеральных вод в Эстонии и др. Заканчивается исследование трещинокарстовых вод Эстонского месторождения горючих сланцев, результаты которого помогут прогнозировать величину притока шахтных вод.

Территория Эстонии граничит на большом протяжении с морем, и 
поэтому одним из вопросов гидрогеологии, изучаемых сейчас в республике, является выяснение взаимовлияния подземных вод суши и вод моря, в особенности выяснение условий осолонения морскими водами подземных вод в разных геологических и геоморфолотических условиях. Начаты исследования по выяснению характеристики подземного стока на территории Әстонии, которая должна дать научно-технические основы для составления баланса и выяснения естественных ресурсов подземных вод республики. Выполняются специальные исследования по гидростратиграфии и характеристике движения подземных вод.

Новым научно-исследовательским направлением в республике, получившим развитие лишь после войны, является инженерная геология. В Институте геологии в конце 50-х - начале 60-х годов был составлен сводный обзор инженерно-геологических условий и инженерно-геологического районирования Эстонии. Была дана инженерно-геологическая классификация пород на основании генетических принципов, что позволило подразделить коренные породы на четыре, а четвертичные - на три геологические формации и последние -- на ряд генетических комплексов, которым даны инженерно-геологические характеристики. Вся территория подразделена на 14 инженерно-геологических формаций. Составленная сводка позволяет правильно направлять планирование строительства в республике и дает общие основы для дальнейших детальных и углубленных инженерно-геологических исследований.

Говоря о развитии геологических наук в Советской Эстонии, необхоцимо обратить внимание и на успешное изучение в течение последнего десятилетия метеоритных кратеров Каали на острове Сааремаа и метеоритных кратеров Илуметса в Юго-Восточной Эстонии, инициатором которого является Метеоритная комиссия при АН ЭССР, организованная в 1954 году.

Все вышеизложенное показывает с достаточной ясностью, насколько расширилось по сравнению с предыдущими периодами изучение геологических проблем в Советской Эстонии. Теперь, кроме Тартуского университета, занимающегося геологическими исследованиями с 20-х годов XIX века, в республике имеются специальные геологические учреждения - Институт геологии АН ЭССР и Управление геологии СМ ЭССР, которые оборудованы всем необходимым для ведения разносторонних геологических исследований на уровне современной науки. Ведется систематическое и планомерное изучение геологии территории Эстонии для решения теоретических проблем и удовлетворения нужд народного хозяйства. Все это смогло осуществиться только благодаря установлению Советской власти в Эстонии.

Все геологи, работающие в геологических учреждениях республики, хорошо понимают это и вместе со всеми геологами Советского Союза торжественно отмечают 50 -летие Великой Октябрьской социалистической революции, открывшей благоприятные условия для бурного развития геологических наук и в Эстонской ССР. Они и в дальнейшем будут прилагать все свои силы и знания, чтобы добиваться новых существенных успехов в изучении геологии республики, способствующих дальнейшему развитию теоретических проблем геологических наук и являющихся прочной основой для решения многих вопросов народного хозяйства - минерального сырья, водоснабжения, строительных грунтов и др., внося тем самым свой вклад в дело укрепления могущества Советского Союза. 30/III 1967 